\title{
Use of short-acting insulin aspart in managing older people with diabetes
}

\author{
Eltayeb Marouf \\ Alan J Sinclair \\ Institute of Diabetes for Older \\ People - IDOP, Bedfordshire \\ and Hertfordshire Postgraduate \\ Medical School, University \\ of Bedfordshire, UK
}

\begin{abstract}
Type 2 diabetes mellitus affects 5.9\% of the world adult population, with older people and some ethnic groups disproportionately affected. Treatment of older people with diabetes differs in many ways from that in younger adults since the majority have type 2 disease and are at particular risk of macrovascular rather than disabling microvascular disease. Insulin therapy, the most effective of diabetes medications, can reduce any level of elevated HBA1c if used in adequate doses. However, some clinicians are often reluctant to initiate insulin therapy in older people with diabetes mainly out of their concerns about adverse reactions to insulin, particularly hypoglycemia. There is evidence suggesting that insulin aspart appears to act similarly to regular human insulin in older people with type 2 diabetes mellitus. Insulin aspart can be used in the treatment of older people with diabetes, but this should be individualized. There is evidence that it improves postprandial glucose control, improves long-term metabolic control, reduces risk of major nocturnal hypoglycemia and increases patient satisfaction compared with soluble insulin.

Keywords: older people, diabetes, insulin aspart, hypoglycemia
\end{abstract}

\section{Introduction}

The global epidemic of type 2 diabetes continues unabated and now affects $5.9 \%$ of the world's adult population. Older people and members of some ethnic groups are disproportionately affected. ${ }^{1}$

An age-associated hyperglycemia phase and glucose intolerance in older people was first described in $1921^{2}$ and has been confirmed on many occasions since. ${ }^{3}$ The clinical presentation of diabetes in older people is often non specific and atypical and as a result the diagnosis is often missed or delayed. In addition older people with diabetes have higher rates of functional, psychological and cognitive impairments, and disabilities. Moreover, older people often have a wide co-morbidity profile linked to the inevitable consumption of multiple medications, and management guidance up to now has been relatively limited due to the lack of focused clinical guidelines, despite the overwhelming evidence base in diabetes generally.

There are no outcome data on the long term effect of tight glycemic control in older people with diabetes, and it is by a process of extrapolation from data on young and middle age diabetic subjects that the management of type 2 older people remains essentially the same as in younger patients. Modification of lifestyle and dietary advice plus the targeted use of single oral agents such as metformin are the most important early management steps. When these measures fail to control the symptoms and improve glycemic control then other oral antidiabetic medications and insulin analogs can be considered. This paper describes the value of using a specific short-duration insulin analog.

\section{Management of diabetes in older people}

The consensus statement from the American Diabetes Association and the European Association for the study of Diabetes published in 2006 on the 
management of hyperglycemia in type 2 diabetes produced a consensus algorithm for the initiation and adjustment of therapy. ${ }^{4}$

Treatment of older people with diabetes differs in many ways from that in younger adults since the majority have type 2 disease and are at particular risk of macrovascular rather than disabling microvascular disease. Treatment approaches therefore need to take particular account of cardiovascular risk factors ${ }^{5}$ particularly in those at home or in care homes. ${ }^{6-7}$ The decision to offer treatment should be based on the likely benefit/risk ratio for the intervention in the individual concerned, but factors such as vulnerability to hypoglycemia, ability to self-manage, the presence or absence of other pathologies, the cognitive status, and life expectancy must be considered.

Concern about hypoglycemia and lack of evidence of benefit has contributed to underutilization of insulin in older people with type 2 diabetes in the past. Following the landmark UKPDS (United Kingdom Prospective Diabetes Study) it is clear that many elderly patients treated with diet and oral antidiabetic agents will develop beta-cell failure and will be at risk of worsening glycemic control with reduced well-being unless insulin is considered. The UKPDS ${ }^{8}$ and Kumamoto University studies ${ }^{9}$ utilized a target $\mathrm{HbA} 1 \mathrm{c}$ level of $7.0 \%$ that may be unrealistic in the context of hypoglycemic risk for many older people. The Steno- 2 study, ${ }^{10}$ which includes treatment of macrovascular risk factors as well as glycemic control, represents a multifactoral approach to managing diabetes that is appropriate for all older people in the context of a healthy aging program combining lifestyle and therapeutic interventions. Recommendations from the European Diabetes Working Party For Older People 2000-2004 (available at www.eugms.org) suggest aiming for a target $\mathrm{HbA} 1 \mathrm{c}$ of $6.5 \%$ to $7.5 \%$ for subjects with single system involvement, with the precise target depending on existing cardiovascular disease, presence of microvascular complications, and ability to self-manage. ${ }^{11}$

\section{Principles of insulin therapy in older people}

Insulin therapy, the most effective of diabetes medications, can reduce any level of elevated $\mathrm{HbA} 1 \mathrm{c}$ if used in adequate doses. However, some clinicians are often reluctant to initiate insulin therapy in older people with diabetes mainly out of their concerns about adverse reactions to insulin, particularly hypoglycemia (Table 1). Hypoglycemic risk can be minimized by initial careful assessment of the patient's
Table I Concerns about the use of insulin in older people

- Hypoglycemia

- Inability to do regular blood sugar monitoring

- Cognitive impairment

- Visual impairment

- Living alone

- Polypharmacy

- Effects of comorbidities

cognitive function, by patient education, and careful selection of treatment options and glycemic targets.

\section{Insulin aspart}

The human insulin analog, insulin aspart, with its proline having been replaced by the negatively charged aspartic acid at position 28 of the B-chain, has an insulin-receptor affinity similar to that of human insulin. ${ }^{12}$

It has a shorter onset and duration of action and can be given immediately before meals. ${ }^{13}$ Its unique molecular structure that its absorption is fast, its action is rapid and that its duration of action is short (Figure 1). Other researchers suggested that subcutaneous injections of insulin aspart just before meals better mimic the endogenous insulin profile in blood compared with human insulin, resulting in improved glucose control in a meal-related insulin regimen. ${ }^{14-16}$

Home et $\mathrm{al}^{17}$ in a 6 -month, prospective, randomized, open-label, parallel study, the effect of insulin aspart on long term glycemic control was compared with soluble human insulin in 1070 patients with type 1 diabetes. The study found that after 8 months treatment, HbAlc was significantly lower (by $0.12 \%$ ) with insulin aspart than soluble human insulin.

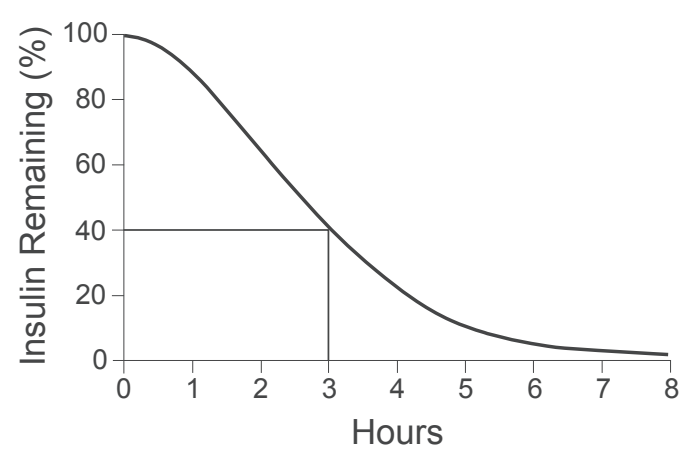

Figure I The timing of action for insulin aspart. A euglycemic clamp is used for delivery of the insulin aspart ( 0.2 units $/ \mathrm{kg}$ of body weight, delivered into the abdomen). The use of this graph helps patients avoid "insulin stacking". For example, 3 hours after the administration of 10 units of insulin aspart, one can estimate that there is still $40 \%$ times 10 units, or 4 units, of insulin remaining. Reproduced with permission from Hirsch IB, Insulin analogues. New Engl J Med. 2005;352:174-183. ${ }^{14}$ Copyright (C) 2005 Massachusetts Medical Society. All rights reserved. 
Treatment satisfaction assessed by the WHO DTSQ (Diabetes Treatment and Satisfaction Questionnaire) was significantly improved with insulin aspart. ${ }^{16}$ The relative risk of a major hypoglycemic episode with insulin aspart compared with soluble human insulin was $0.83(0.59-1.18, \mathrm{NS})$. Major night-time hypoglycemic events requiring parenteral treatment were less with insulin aspart (1.3 vs $3.4 \%$ of patients, $\mathrm{p}<0.05)$. Other studies have also found that insulin aspart is superior to soluble human insulin in controlling post-prandial blood sugar. ${ }^{18}$

A recent evidence-based medicine review of biphasic insulin aspart (BIAsp) 30 in type 2 diabetes mellitus has concluded that the reported efficacy and tolerability of BIAsp 30 in the treatment of diabetes based on a variety of clinical endpoints is supported by a good body of evidence relating to its use in different dosage regimens and in comparison with other insulin treatment regimens. ${ }^{19}$ Chlup et al studied 57 individuals with type 2 diabetes, comparing the use of human regular insulin and insulin aspart, and found that insulin aspart appears to be more effective than human regular insulin. ${ }^{20}$ Moreover, another short-acting insulin (insulin glulisine) was found to provide a small improvement in glycemic control compared with regular human insulin in patients with type 2 diabetes who are already relatively very well controlled in insulin alone or insulin plus oral hypoglycemic agents. ${ }^{21}$

\section{Use of insulin aspart in older people}

Studies comparing insulin aspart and regular insulin in elderly patients with type 2 diabetes have been conducted by Meneilly. ${ }^{22}$ The aim of the studies was to evaluate the pharmacokinetic and pharmacodynamic properties of insulin aspart in older people with diabetes. They studied 19 patients (10 males and 9 females), age $72 \pm 1$ years, BMI $27 \pm 1 \mathrm{~kg} / \mathrm{m}^{2}$ and $\mathrm{HbA1c} 6.4 \pm 0.1 \%$, diabetes duration $<5$ years; 9 patients were treated with metformin and 10 patients with diet. In a random order the subjects underwent 2 studies.

In one study, 0.1 units $/ \mathrm{kg}$ of regular insulin were administered at 7:30 AM. Thirty minutes later at time 0 subjects were given $235 \mathrm{~mL}$ of Ensure Plus Fibre ${ }^{\circledR}$ (Abbott). The other study was identical to the first study except that insulin aspart 0.1 units $/ \mathrm{kg}$ was given at time zero. Insulin and glucose values were measured at regular intervals. The results indicate that insulin aspart appears to act similarly to regular human insulin in older people with type 2 diabetes (Figure 2).

Warren et al, ${ }^{23}$ in a multi-center open-label randomized cross-over two-arm study of 10 weeks' treatment, also looked at post-prandial versus pre-prandial dosing of BIAsp 30 in
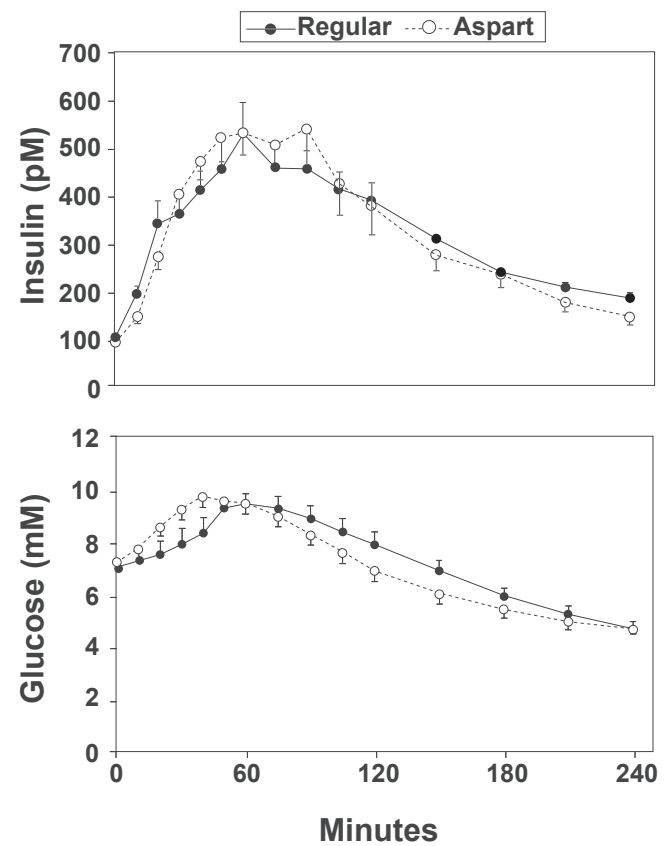

Figure 2 Insulin and glucose values during the test meal in response to regular insulin and insulin aspart in 19 patients ( 10 males and 9 females), age $72 \pm 1$ years, BMI $27 \pm \mathrm{I} \mathrm{kg} / \mathrm{m}^{2}$ and $\mathrm{HbAlc} 6.4 \pm 0.1 \%$ and diabetes duration $<5$ years. Reproduced with permission from Meneilly GS. A comparison of insulin aspart and regular insulin in elderly patients with type 2 diabetes. Diabetes Obes Metab. 2007;9(5):754-755. ${ }^{22}$ Copyright (? 2007 Blackwell Publishing.

elderly type 2 diabetes patients. Their conclusion was that post-prandial injection of BIAsp 30 may be an acceptable alternative to minimize the risk of hypoglycemia for some older people with type 2 diabetes (Figure 3).

In a sub-group analysis, ${ }^{24}$ the efficacy, safety and treatment satisfaction of insulin aspart was evaluated in elderly patients with type 2 diabetes in the PRESENT Korea NovoMix study. In this 6-month, prospective study, patients inadequately controlled on previous therapies achieved better glycemia (reduction of $\mathrm{HbAlc}$ of $1.2 \pm 1.6 \%$; reductions of fasting plasma glucose and post-prandial glucose of $2.3 \pm 3.5 \mathrm{mmol} / \mathrm{L}$ and $4.8 \pm 5.3 \mathrm{mmol} / \mathrm{L}$ at 6 months, respectively, $\mathrm{p}<0.0001$ for all). Hypoglycemia rates were lower and weight gain was minimal. Treatment satisfaction was greater than $80 \%$.

Miyashita et al conducted a prospective, randomized study for optimal insulin therapy in type 2 diabetic patients with secondary failure and found that both basal-bolus therapy with the ultra rapid-acting insulin analog and conventional therapy with the twice daily BIAsp produce comparable reduction in HbAlc in type 2 diabetic patients with secondary failure. ${ }^{25}$ With particular reference to elderly and given that their appetite may be unstable, it may be preferable to treat them with a fast-acting insulin eg, insulin aspart, the dose of which is dependable on the actual amount of food consumed. 

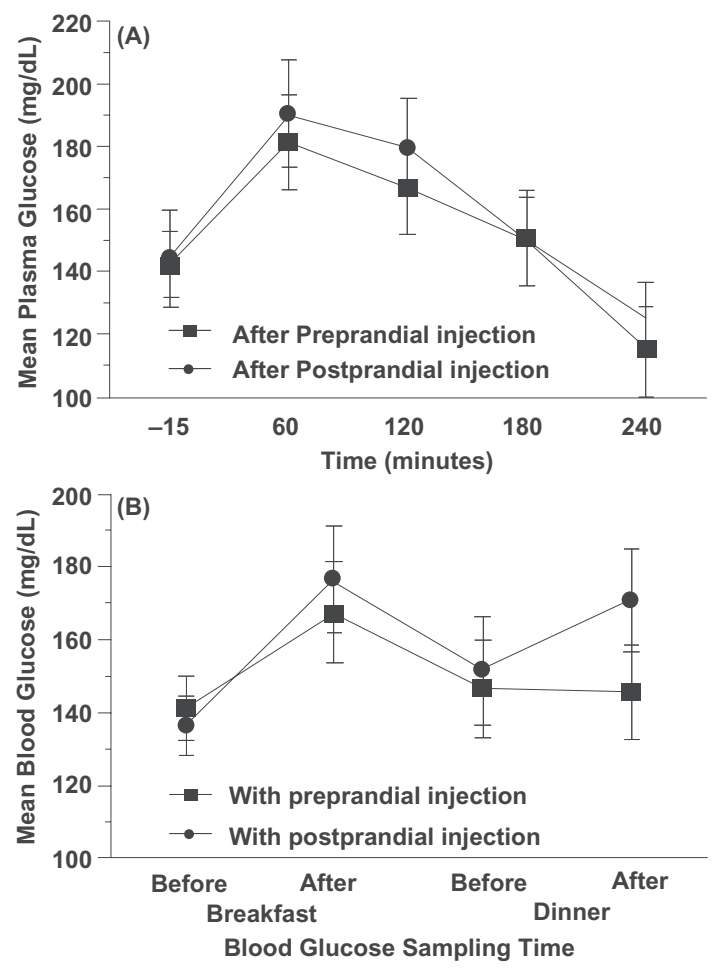

Figure 3 Glycemic profiles at the end of each treatment period. Ninety-three elderly patients ( $\geq 65$ years) were treated with bid pre-prandial injections of BIAsp 30 during a 2-week run-in period and subsequently randomized to a 4-week treatment with either pre- or post-prandial bid BIAsp 30, followed by crossover to the other regimen for 4 weeks. Reproduced with permission from Warren ML, Conway MJ, Klaff LJ, Rosenstock J, Allen E. Postprandial versus preprandial dosing of biphasic insulin aspart in elderly type 2 diabetes patients. Diabetes Res Clin Pract. 2004;66(I):23-29. ${ }^{23}$ Copyright @ 2004 Elsevier.

With this increasing evidence base, the European Commission announced in September, 2007, their approval of rapidly acting insulin aspart (NovoRapid ${ }^{\circledR}$; Novo Norkisk) in the treatment of diabetes in elderly patients.

\section{Conclusion}

Insulin aspart can be used in the treatment of older people with diabetes; however this treatment should be individualized. There is evidence that it improves post-prandial glucose control, improves long-term metabolic control, reduces risk of major nocturnal hypoglycemia and increases patient satisfaction compared with soluble insulin.

\section{Disclosures}

The authors have no conflicts of interest to declare.

\section{References}

1. Sinclair AJ, Croxson SCM. Diabetes mellitus. In: Tallis RC, Fillit HM, editors. Brocklehurst's textbook of geriatric medicine and gerontology, 6th ed. London: Churchill Livingstone; 2003. p. 1193-1218.

2. Spence JC. Some observations on sugar tolerance with special reference to variations found at different ages. QJ Med. 1921;14:314-326.
3. Davidson MB. The effect of aging on carbohydrate metabolism: a review of the English literature and a practical approach to the diagnosis of diabetes mellitus in the elderly. Metabolism. 1979;28(6):688-705.

4. Nathan DM, Buse JB, Davidson MB, et al. Management of hyperglycaemia in type 2 diabetes: a consensus algorithm for the initiation and adjustment of therapy. Diabetolgia. 2006;49:1171-1721.

5. Hendra TJ, Sinclair AJ. Improving the care of elderly diabetic patients: the final report of the St Vincent Joint Task Force for diabetes. Age Ageing. 1997;26:3-6.

6. Sinclair AJ, Turnbull CJ, Croxson SCM. Document of care for older people with diabetes. Postgrad Med J. 1996;72:334-338.

7. Sinclair AJ, Turnbull CJ, Croxson SCM. Document of diabetes care for residential and nursing homes. Postgrad Med J. 1997;73:611-612.

8. UK Prospective Diabetes Study (UKPDS) Group. Intensive bloodglucose control with sulphonylureas or insulin compared with conventional treatment and risk of complications in patients with type 2 diabetes (UKPDS 33). Lancet. 1998;352:837-853.

9. Ohkubo Y, Kishikawa H, Araki E, et al. Intensive insulin therapy prevents the progression of diabetic microvascular complications in Japanese patients with non-insulin-dependent diabetes mellitus: a randomized prospective 6-year study. Diabetes Res Clin Pract. 1995;28:103-117.

10. Gaede P, Vedel P, Larsen N et al. Multifactorial intervention and cardiovascular disease in patients with type 2 diabetes. $N$ Engl J Med. 2003;348:383-393.

11. European Diabetes Working Party For Older People 2000-2003. Clinical Guidelines for Type 2 Diabetes Mellitus. Available from: www.eugms.org.

12. Simpson KL, Spencer CM. Insulin aspart. Drugs. 1999;57:759-765.

13. Lindholm A, Jacobsen LV. Clinical pharmacokinetics and pharmacodynamics of insulin aspart. Clin Pharmacokinet. 2001;40:641-659.

14. Hirsch IB, Insulin analogues. New Engl J Med. 2005;352:174-183.

15. Mudaliar S, Lindberg FA, Joyce M, et al. Insulin aspart (B28 Asp-insulin): a fast-acting analog of human insulin: absorption kinetics and action profile compared with regular human insulin in healthy nondiabetic subjects. Diabetes Care. 1999;22:1501-1506.

16. Østerberg O, Erichsen L, Ingwersen SH, Plum A, Poulsen HE, Vicini P. Pharmacokinetic and pharmacodynamic properties of insulin aspart and human insulin. J Pharmacokinet Pharmacodyn. 2003;30:221-235.

17. Home PD, Lindholm A, Riis A. Insulin aspart vs human insulin in the management of long-term blood glucose control in type 1 diabetes mellitus: a randomized controlled trial. Diabet Med. 2000;17:762-770.

18. Raskin P, Guthrie RA, Leiter L, Riis A, Jovanovic L. Use of insulin aspart, a fast-acting insulin analog, as the mealtime insulin in the management of patients with type 1 diabetes. Diabetes Care. 2000;23(5):583-588.

19. Gough SCL, Tibaldi J. Biphasic insulin aspart in type 2 diabetes mellitus: an evidence-based medicine review. Clin Drug Invest. 2007;27(5):299-324.

20. Chlup R, Zapletalova J, Seckar P, et al. Benefits of complementary therapy with insulin aspart versus human regular insulin in persons with type 2 diabetes mellitus. Diabetes Technol Ther. 2007;9(3):223-231.

21. Dailey G, Moses R, Rosenstock J, et al. Insulin glulisine provides improved glycemic control in patients with type 2 diabetes. Diabetes Care. 2004, 27:2363-2368

22. Meneilly GS. A comparison of insulin aspart and regular insulin in elderly patients with type 2 diabetes. Diabetes Obes Metab. 2007;9(5):754-755.

23. Warren ML, Conway MJ, Klaff LJ, Rosenstock J, Allen E. Postprandial versus preprandial dosing of biphasic insulin aspart in elderly type 2 diabetes patients. Diabetes Res Clin Pract. 2004;66(1):23-29.

24. Jang HC, Lee SR, Vaz JA. Biphasic insulin aspart 30 in the treatment of eldserly patients with type 2 diabetes: a subgroup analysis of the PRESENT Korea NovoMix study. Diabetes Obes Metab. 2009;11(1):20-26.

25. Miyashita Y, Nishimura R, Nemoto M, Matsudaira T, et al. Prospective randomized study for optimal insulin therapy in type 2 diabetic patients with secondary failure. Cardiovasc Diabetol. 2008;7:16 doi:1186/1475-2840-7-16. 